\title{
Correction to: Structural and myocardial dysfunction in heart failure beyond ejection fraction
}

\author{
Paolo Severino ${ }^{1}$. Viviana Maestrini ${ }^{1} \cdot$ Marco Valerio Mariani ${ }^{1} \cdot$ Lucia Ilaria Birtolo ${ }^{1} \cdot$ Rossana Scarpati $^{1}$. \\ Massimo Mancone ${ }^{1} \cdot$ Francesco Fedele $^{1}$
}

Published online: 24 August 2019

(C) The Author(s) 2019

\section{Correction to: Heart Fail Rev \\ https://doi.org/10.1007/s10741-019-09828-8}

The original version of this article unfortunately contained a mistake. Unfortunately one of the author's last name is misspelled: the correct name is Viviana Maestrini. The original article has been corrected.

Open Access This article is distributed under the terms of the Creative Commons Attribution 4.0 International License (http:// creativecommons.org/licenses/by/4.0/), which permits unrestricted use, distribution, and reproduction in any medium, provided you give appropriate credit to the original author(s) and the source, provide a link to the Creative Commons license, and indicate if changes were made.

Publisher's note Springer Nature remains neutral with regard to jurisdictional claims in published maps and institutional affiliations.

The online version of the original article can be found at https://oi.org/ 10.1007/s10741-019-09828-8

Francesco Fedele

francesco.fedele@uniroma1.it

1 Department of Cardiovascular, Respiratory, Nephrology, Anesthesiology and Geriatric Sciences, Sapienza University of Rome, Rome, Italy 